\title{
REVIEW ARTICLE OPEN Probing the formation and degradation of chemical interactions from model molecule/metal oxide to buried polymer/metal oxide interfaces
}

\author{
Sven Pletincx (D) ${ }^{1}$, Laura Lynn I. Fockaert ${ }^{2}$, Johannes M. C. Mol $\mathbb{D}^{2}$, Tom Hauffman ${ }^{1}$ and Herman Terryn ${ }^{1}$
}

The mechanisms governing coating/metal oxide delamination are not fully understood, although adhesive interactions at the interface are considered to be an important prerequisite for excellent durability. This review aims to better understand the formation and degradation of these interactions. Developments in adhesion science made it clear that physical and chemical interfacial interactions are key factors in hybrid structure durability. However, it is very challenging to get information directly from the hidden solid/solid interface. This review highlights approaches that allow the (in situ) investigation of the formation and degradation of molecular interactions at the interface under (near-)realistic conditions. Over time, hybrid interfaces tend to degrade when exposed to environmental conditions. The culprits are predominantly water, oxygen, and ion diffusion resulting in bond breakage due to changing acid-base properties or leading to the onset of corrosive de-adhesion processes. Therefore, a thorough understanding on local bond interactions is required, which will lead to a prolonged durability of hybrid systems under realistic environments.

npj Materials Degradation (2019)3:23; https://doi.org/10.1038/s41529-019-0085-2

\section{INTRODUCTION}

One of the most common methods to protect engineering metals against corrosion is by the application of an organic overlay. Examples of these polymer/(hydr)oxide/metal systems can be widely found in several industrial domains. In aerospace, microelectronics, packaging, and even biomedical industry engineering metals are coated by a polymer overlayer. ${ }^{1}$ The most straightforward examples can be found in infrastructure (e.g., paints on buildings and bridges) and in transport (e.g., lacquer on cars, ships, air planes, and spaceships). These organic coatings are applied in order to protect the underlying substrate against corrosion by hostile, atmospheric conditions. Furthermore, they are also used to provide additional functional properties to the system by the addition of several components such as pigments, fillers, curing agents, corrosion inhibitors, etc. (e.g., color, wear resistance, thermal protection, light reflection, hydrophobicity or hydrophilicity, electrical and thermal conductivity, insulation, etc.). ${ }^{1}$ These organic coatings often need to be able to withstand mechanical forces, changes in temperature and long-time exposure to hostile environments. Unfortunately, the protecting ability of the organic coating against degradation agents is not infinite and sooner or later the hybrid system will degrade, leading to delamination of the organic coating and/or the onset of corrosion of the metal substrate.

Studying interfacial interactions is not an easy task. This is mainly because the $\mu \mathrm{m}$-thick polymer layer is masking the interface region, making it difficult for conventional analysis techniques to investigate this region. Therefore, this region is usually called the buried interface and specific methodologies are required to obtain local and buried chemical information. The adsorption theory of adhesion states that two phases stick due to intermolecular interactions that involve both physical and chemical bonding. Physical adsorption involves van der Waals forces across the interface. The term Van der Waals force corresponds to three interactions, more specificity the London, Keesom, and Debye interactions. Dispersion (or London) interactions arise from electron cloud motions, independent of dipole interactions. These are the weakest forces that always contribute to adhesive bonds but are only felt by the molecules at the interface that are in close contact. The attraction between permanent dipoles (Keesom) and induced dipoles (Debye) are the polar forces that arise between polarized or polarizable molecules. Another force that can arise is the hydrogen bond, resulting from the electronegativity between a hydrogen atom and a strongly electronegative atom. Notwithstanding their relatively weak bond strength, physical adsorption already can lead to strong adhesive interactions on the macroscopic level. Chemical bonding theory involves the formation of covalent and ionic bonds across the interface by acid-base interactions. ${ }^{2}$ An overview of the different types of bonds and their characteristics are shown in Table 1.

Achieving high-adhesion strengths in day-to-day conditions is the main goal of hybrid interface engineering. Over the last 40 years, it became possible to demonstrate the significant contribution of adsorption theory to overall adhesion due to the development of a wide variety of (surface) analysis techniques and the application of specific accessing methodologies. ${ }^{4-8}$

In this review paper, we will first focus on metal oxide properties that influence the type and amount of formed bonds. This is

\footnotetext{
${ }^{1}$ Department of Materials and Chemistry (MACH), Electrochemical and Surface Engineering Research Group (SURF), Vrije Universiteit Brussel, Pleinlaan 2, 1050 Brussels, Belgium and ${ }^{2}$ Department of Materials Science and Engineering, Delft University of Technology, Mekelweg 2, 2628 CD Delft, The Netherlands

Correspondence: Sven Pletincx (Sven.Pletincx@vub.be)
}

Received: 11 February 2019 Accepted: 15 May 2019

Published online: 06 June 2019 


\begin{tabular}{|c|c|c|}
\hline Bond type & $\begin{array}{l}\text { Bond energy } \\
\left(\mathrm{kJ} \mathrm{mol}{ }^{-1}\right)\end{array}$ & $\begin{array}{l}\text { Equilibrium } \\
\text { length (nm) }\end{array}$ \\
\hline \multicolumn{3}{|l|}{ Primary, chemical } \\
\hline Ionic & $600-1000$ & $0.2-0.4$ \\
\hline Covalent & $60-800$ & $0.1-0.3$ \\
\hline Metallic & $100-350$ & $0.2-0.6$ \\
\hline \multicolumn{3}{|l|}{ Acid-base interactions } \\
\hline Conventional Brø nsted & $<1000$ & \\
\hline Lewis & $<80$ & \\
\hline \multicolumn{3}{|l|}{ Secondary, physical } \\
\hline Hydrogen & 50 & 0.3 \\
\hline \multicolumn{3}{|l|}{ Van der Waals } \\
\hline London dispersion & $1-40$ & $<1$ \\
\hline Keesom orientation & $2-8$ & 0.4 \\
\hline Debye induction & $<2$ & 0.4 \\
\hline
\end{tabular}

followed by different strategies for the direct characterization of the formation of ionic interactions at the interface of polymer/ metal oxide systems. Additionally, this review will provide an overview of new methodologies that can give an in situ insight in the degradation processes occurring locally at the hybrid interface, monitored under (near-)ambient conditions. We will focus on the degradation of interfacial interactions from a local perspective at the hybrid interface. The main factors that govern delamination on a molecular level are water, oxygen, and ions such as chlorides. Over time, these components will reach the interface and start a variation of reactions such as corrosion, hydrolysis, or replacement of interactions that eventually lead to the disappearance of the initially formed bonds. The discussion is concluded by reviewing the role of covalent bonding explaining the use of silanes as adhesion promoters on metal oxide substrates. This review does not focus on overall coating delamination on a macroscopic level as a result of electrochemical corrosion reactions, such as cathodic or anodic delamination. For a more in-depth discussion on corrosive de-adhesion, the reader is referred to other literature. ${ }^{6,9}$

\section{THE IMPORTANCE OF ORGANIC/INORGANIC ADHESION ON OVERALL COATING PERFORMANCE}

Despite the extensive amount of research and testing, the mechanisms leading to coating failure are still not fully understood. Several hypotheses have been proposed, but the current conclusion is that there is no single protective mechanism operative in organic coatings. ${ }^{10}$ Aside from failure due to cracks in the coatings or due to defects sustained during the service life of the hybrid system, coatings provide a barrier against the environment by providing a high resistance to the movement of water and ions. ${ }^{11}$ Lyon et al. poses a number of questions that still need to be addressed in order to develop a mechanistic understanding of the coating performance over time and under various service conditions. The overall goal of hybrid interfacial engineering is the development of a predictive toolkit for coating failure. This predictive toolkit is required to shorten the development time of new coating formulations and to predict the behavior of coatings under service conditions. Currently, the durability of hybrid systems is monitored by extensive empirical testing, but an in-depth scientific understanding of all the key mechanism leading to failure is still required. This scientific understanding should be achieved by both numerical modeling, as well as newly developed experimental approaches.

One of the key mechanism behind the coating durability involves the interaction behavior between the polymer and metal oxide. Funke et al. ${ }^{12}$ were one of the first groups to highlight the importance of (wet) adhesion at the interface of hybrid systems. The Funke hypothesis states that chemical interactions at the interface are governing the durability of the entire coating. Therefore, a high (wet) adhesion strength at the interface must be a prerequisite for a high durability of the entire coating. Furthermore, also the importance of the amount of bonds at the interface is highlighted. During the application of a coating, the time of adsorption is limited, as the coating has to solidify very fast. Owing to this fast solidification, no equilibrium state can be reached at the interface, possibly leading to less interfacial bonds. Therefore, bond formation at the interface must be faster than the occurring polymer curing reaction. This was investigated by Taheri et al. ${ }^{13}$, where they showed that the curing reaction of propoxylated bisphenol A fumarate unsaturated polyester continued after the completion of the ionic bond formation at the zinc oxide interface. It has been shown that the application of ultrathin polymer layers from dilute solutions can improve the wet adhesion strength. ${ }^{14-16}$ Funke proposed that this effect occurs at a concentration range in which the macromolecules have minimal competition for adsorption sites on the surface and are able to form a non-ordered kind of monolayer with a maximum amount of adsorbed functional groups. ${ }^{17}$

Therefore, it can be concluded that a good coating adhesion is a minimal requirement, in combination with high-barrier properties and active corrosion protection, in order to obtain a high-coating performance. $^{10} \mathrm{~A}$ meticulous understanding of the interfacial interactions is thus an indispensable requirement in the challenge to engineer durable hybrid systems. This review highlights the developments in the understanding of this key mechanism to eventually engineer more durable hybrid systems and to be able to predict overall coating failure.

\section{THE EFFECT OF DIFFERENT SUBSTRATE PROPERTIES ON INTERFACIAL INTERACTIONS}

Before we elaborate further on the characterization and different probing methodologies, it is important to highlight some properties of the metal oxide substrate that have an influence on the type and amount of bonds that can be formed with a polymer overlayer. This is illustrated in Fig. 1, showing that different pretreatments applied to a metal oxide surface (e.g., aluminum oxide) lead to a variation in the overall adhesion strengths. ${ }^{18}$ This observation shows the importance of multiple surface oxide properties. The electronic structure, chemical composition, morphology (including oxide thickness and roughness) and acid-base character of the surface oxide were all proven to influence adhesion. ${ }^{19-21}$ By the application of different pretreatments, the nature of the surface oxides can be altered. It thus becomes possible to alter these properties in order to obtain durable bonds. $^{22-25}$

The utilization of surface analytical techniques provides nowadays a thorough characterization of the top-surface layer of materials. Changes in the composition and chemical state of metal oxides can be characterized by X-ray photoelectron spectroscopy (XPS) and Auger electron spectroscopy (AES). These techniques can be combined with different sputtering techniques that allow the construction of depth profiles. ${ }^{26}$ Both XPS and AES allow the identification of chemical composition and different chemical states of atoms near the surface.

Surface hydroxyl groups and incompletely coordinated metal cations on the oxide layer have a large impact on the type and the amount of formed chemical interactions at the polymer/metal oxide interface. ${ }^{27-33}$ Abrahami et al. ${ }^{34}$ showed by XPS analysis that 


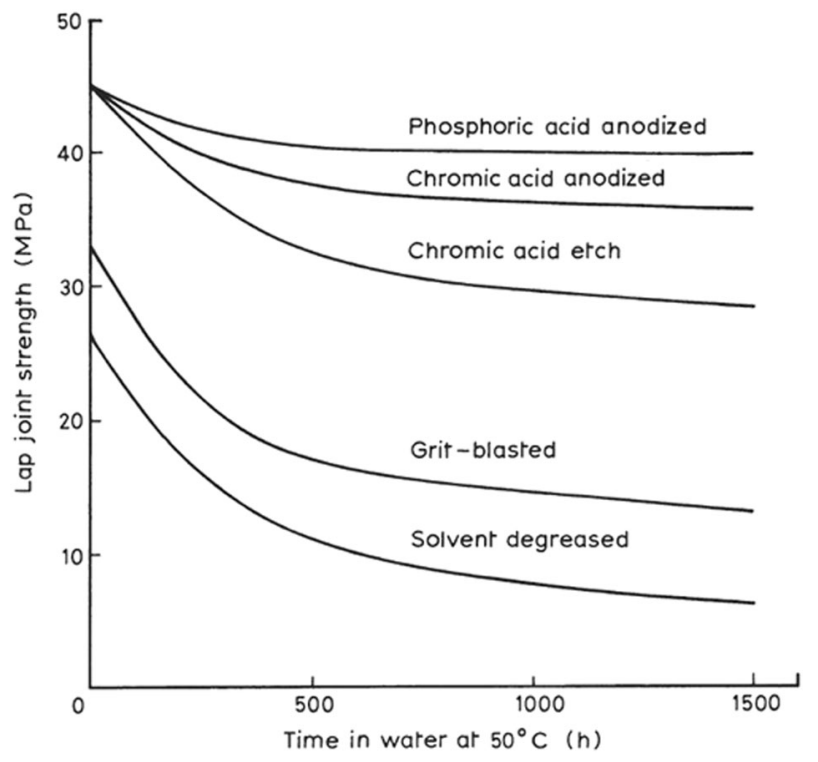

Fig. 1 Lap joint strength (MPa) values for differently pretreated surfaces of aluminum alloy with an epoxy coating immersed in water at $50^{\circ} \mathrm{C}$. Indicating the macroscopic effect of the surface pretreatment on the overall durability of the hybrid system. ${ }^{18}$ Reprinted by permission from Springer Nature: Springer Nature, Adhesion and Adhesives by A.J. Kinloch, Copyright (1987)

incorporated anions, such as phosphates and sulphates, embedded in an anodized aluminum oxide layer, reduce the amount of available surface hydroxyls required for bonding. This is linked to a reduced peel strength under wet conditions, highlighting the importance of the amount of free surface hydroxyl groups. The electronic properties of the oxide have also been correlated to the hydroxyl fraction and oxide thickness, monitored by scanning Kelvin probe (SKP). ${ }^{20,32}$

The macroscopic measure for the metal oxide surface's acid-base characteristics is the iso-electric point (IEP) of the surface, where a high IEP indicates a basic surface and a low value resembles an acidic surface. This surface charge directly affects the compatibility and the wetting ability of the polymer and the oxide surface, as well as the bonding mechanism and amount of bonds that are formed. ${ }^{35} \mathrm{~A}$ high wettability of the oxide surface by the polymer layer is required since a close molecular contact is needed to form an adhesive bond and to have a high coverage of the coating. The different chemical nature of the polymer and oxide surfaces determine their surface tensions and the amount of contact at equilibrium. Surface energy is also sensitive to oxide structure and morphology and can thus also be tuned by the application of a surface pretreatment. A substrate pretreatment is always necessary to achieve a satisfactory level of long-term bond strength. Different pretreatments types exist: physical, mechanical, chemical, photochemical, thermal, or plasma pretreatments have been developed. An extensive review on the different types of pretreatments and their effect on surface properties, such as surface roughness, surface tension, and surface chemistry was performed by Baldan et al. ${ }^{24}$

\section{EXTERNAL INFLUENCES AFFECTING POLYMER/METAL OXIDE INTERACTIONS}

Since solvents are abundantly present in some polymer/metal oxide deposition techniques and are often utilized for industrial polymer applications (volatile organic components or VOCs), it is

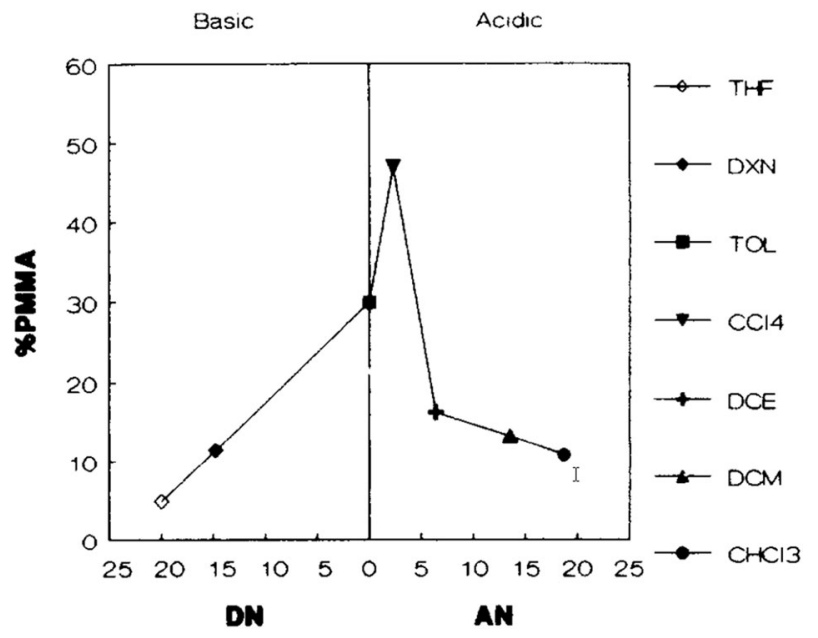

Fig. 2 Amount of PMMA deposited on the surface of chloridedoped polypyrrole as a function of the acid-base properties of the solvent, characterized by Gutmann's donor (DN) and acceptor (AN) parameters. The amount of deposited polymer is determined by XPS analysis. ${ }^{36}$ Reprinted from Abel et al., Copyright (1994), with permission from Elsevier

important to highlight the effect of the used solvent on the interfacial interactions.

The solvent molecules also have acid-base properties that can result in interactions with the to-be deposited polymer and/or the substrate surface, this can have an influence on the total amount of polymer deposited on the metal oxide surface. Fowkes et al. ${ }^{2}$ showed that the nature of the solvent influences the amount of polymer deposited on the surface by mathematically correlating the acid-base interactions of all polar and hydrogen interactions. This showed that the adsorption of polymers onto fillers is dominated by the polymer, the filler and the solvent's acid-base properties. Additionally, this mathematical prediction was shown to be valid by performing adsorption-desorption experiments of poly(methyl methacrylate) (PMMA) on acidic and basic adsorption sites and this from a variation of solvents.

Abel et al. $^{36}$ extended this approach by utilizing XPS to show that the amount of polymer, PMMA, adsorbed on chloride-doped polypyrrole is dependent on the nature of the solvent. ${ }^{36}$ The main conclusion from this work is that the maximum amount of PMMA can only adsorb from neutral solvents, since then the solvent does not compete with the substrate surface to form molecular interactions with the polymer. When the deposition occurs from more basic or acidic solvents, less polymer will be deposited due to a competing effect. In Fig. 2, the amount of PMMA deposited on the surface of chloride-doped polypyrrole as a function of the acid-base properties of the solvent, characterized by Gutmann's donor (DN) and acceptor (AN) parameters, is shown. Here, the amount of deposited PMMA is quantified by XPS. From this plot, the effect of the acid-base properties on the amount of deposited polymer is clearly observed. Moreover, the amount of adsorbed polymer was related to the solvent power, measured by the solubility parameter, and the solvent viscosity but could not fully describe the observations. Abel et al. state that an interpretation in terms of acid-base properties is much more reliable.

However, the interactions occurring between the polymer, the substrate and the solvent have a dynamic nature. ${ }^{37}$ Therefore, the application of an in situ technique is required to monitor the kinetics of these processes. One technique that allows the in situ analysis of the interactions occurring between solvent molecules and metal oxides is odd random phase multisine electrochemical impedance spectroscopy (ORP-EIS). Interactions between ethanol 
and aluminum oxide were characterized by Hauffman et al. ${ }^{38}$ For ORP-EIS, a random phase multisine excitation signal is applied that contains only odd harmonics. This allows to investigate the adsorption process in situ and in a shorter time-frame, which is not possible when singlesine impedance spectroscopy is applied. Additionally, a statistic analysis of the noise levels allows to characterize linear and stationary behavior of the system under perturbation. By adding infrared spectroscopy in the Kretschmann geometry, this approach can be extended to provide information on the chemical interactions at the interface. Pletincx et al. ${ }^{39}$ observed that physisorbed methanol and adventitious carbon are replaced at the interface when an aluminum oxide surface is exposed to methanol. This replacement step is followed by chemisorption of methanol to form methoxide species with the surface hydroxyl groups of the metal oxide. This is achieved by monitoring the adsorption behavior between methanol and the aluminum oxide surface as a function of time by an integrated setup based on IR in the Kretschmann geometry and ORP-EIS.

The risk exists that the solvent undergoes competing adsorption with the polymer during coating deposition. This might lead to the consumption of potential surface adsorption sites by the solvent, instead of the coating, and thus decreasing the overall polymer adhesion. However, also the interaction kinetics need to be considered for the optimization of the polymer/metal oxide interactions.

Generally, the effect of the solvent is not taken into account when depositing a polymer on a metal oxide surface from a polymer solution. Even though a large abundance of the solvent molecules is brought in contact with the oxide surface. This section highlighted the impact of the solvent choice on the overall amount of deposited polymer and shows that a careful selection of the solvent is required to maximize the chemical interactions occurring at the polymer/metal oxide interface.

The ageing of the substrate surface also has an influence on its bonding properties. The adsorption of carbon contamination immediately occurs upon exposure of the oxide surface to the atmosphere. The adsorption of an adventitious carbon layer from the environment leads to the formation of a contamination layer that blocks potential surface bonding sites. ${ }^{40}$ This form of contamination can not be removed by a cleaning step, but is likely replaced during polymer deposition. More significant and thicker layers of contamination such as weak-boundary layers, grease or other organic contamination require the introduction of a cleaning step to optimize overall adhesion. Several cleaning strategies exist that are often required pretreatment steps to ensure good adhesion. An overview of these approaches is given elsewhere. $^{22}$

Another parameter affecting the occurrence of interactions is the effect of ambient water on the metal oxide surface. Often, the formation of a condensed layer on the surface prohibits the formation of bonds. However, the adsorption of water on the oxide surface leads to hydroxylation, which is considered as a positive effect for bonding as more surface hydroxyl groups are formed. $^{40,41}$

\section{AN IN SITU ANALYSIS OF IONIC INTERFACIAL INTERACTIONS FROM MODEL MOLECULE/METAL OXIDE TO BURIED POLYMER/METAL OXIDE INTERFACE}

The deposition of model molecules on metal oxide surfaces The most straightforward way to study the interaction of functional groups with surfaces is by using model molecules. These molecules consist of a similar composition and mimic organic functionalities of the organic coating of interest. In order to study these interactions in situ, the use of (vibrational) spectroscopic techniques is well suited. ${ }^{5}$

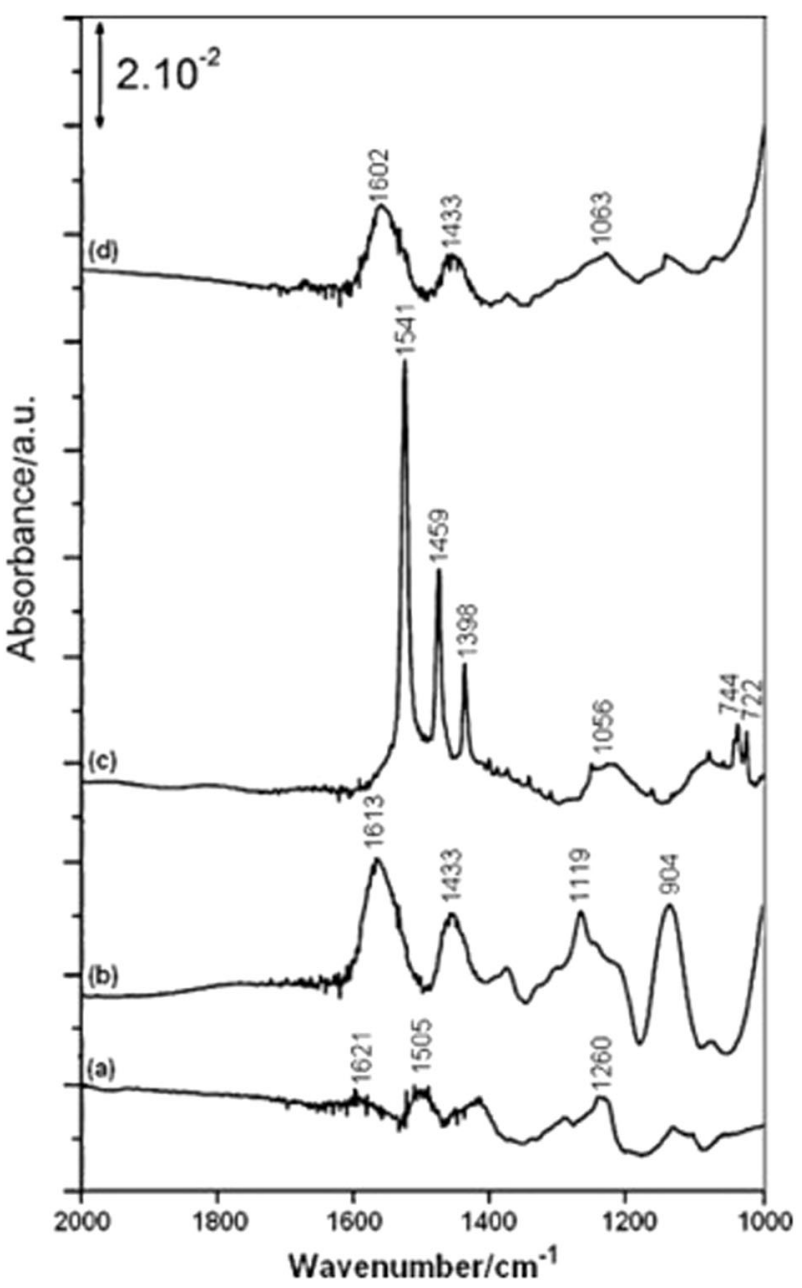

Fig. 3 IRRAS spectra of a bare zinc surface and adsorbed $\mathbf{b}$ succinic acid, c myristic acid, and $\mathbf{d}$ succinic anhydride molecules on zinc surface samples w.r.t. a bare zinc surface. ${ }^{44}$ Reprinted from Taheri et al., Copyright (2011), with permission from Elsevier

The application of infrared reflectance absorbance spectroscopy (IRRAS) is used to study adsorption and desorption of molecules on metal (oxide) surfaces. However, in order to achieve a good signal-to-noise ratio, a highly reflective substrate surface is required and only very thin films of the organic phase can be applied to study the interfacial interaction. When studying carboxylic acid molecules, it was observed that ionic bonds formed between metal oxides substrates and the molecules. This was observed by Van den Brand et al. ${ }^{42}$ when studying the interaction between anhydride and carboxylic acid compounds with aluminum oxide. The formation of ionic bonds was concluded from the presence of symmetric and asymmetric carboxylate stretching bands. Also the formation of physisorbed interactions could be identified by IRRAS. Beentjes et al. ${ }^{43}$ showed that ester functional groups physisorb onto steel surfaces and form hydrogen bonds. When investigating the interaction behavior of differently pretreated zinc substrates and succinic anhydride, Taheri et al. ${ }^{44}$ showed the interesting cyclic behavior of carbonate behavior of the molecule. A combination of IRRAS, shown in Fig. 3 and XPS showed that the anhydride ring structure opens at the surface due to a hydrolysis reaction. Furthermore, the interaction of myristic and succinic acid on zinc surfaces were identified by IRRAS.

An interesting ability of vibrational spectroscopic techniques is the possibility to determine the orientation of the adsorbed 
molecules. This is achieved by the application of polarized light. Since only the $\mathrm{p}$-component of the IR light interacts with the surface of sample, the active vibrations that can be detected in IRRAS must have a component of the dynamic dipole polarized in the direction normal to the surface of sample. Polarization modulated IRRAS (PM-IRRAS) has been applied on adsorbed organosilane molecules containing an urea group on silicon oxide surfaces. Owing to the selection rule, Ramin et al. ${ }^{45}$ found that the carbonyl groups of the urea are oriented parallel to the substrate, thus promoting the formation of hydrogen bonding between the urea groups and the substrate. For myristic acid adsorption on aluminum oxide, a carboxylate bond was observed. The orientation could be determined on the equal intensities of the symmetric and asymmetric stretch in the spectrum, indicating a tipped geometry. ${ }^{42}$

In situ IRRAS can also be used to study the interfacial stability in water-rich environments. Maxisch et al. ${ }^{46,47}$ studied octadecylphosphonic acid (ODPA) monolayers on aluminum oxide substrates in the presence of water. No changes were observed in the interfacial interactions or in the ordering of the alkyl chains during water adsorption. Interestingly, when using deuterated water, a proton exchange process between the $\mathrm{D}_{2} \mathrm{O}$ molecules and the ODPA at the interface was discovered. This would have otherwise been obscured in the spectrum by the contribution of $\mathrm{H}_{2} \mathrm{O}$ molecules.

XPS is a spectroscopic surface analysis technique that can also be utilized to study interfacial interactions. This technique results in surface-sensitive chemical state information and is thus well suited for the study of molecule/substrate interactions. Abrahami et al. $^{34}$ investigated the adsorption of diethylentriamine (DETA), an amine model molecule, on differently anodized aluminum oxide surfaces. The type of acid-base interactions could be identified by determining changes in the binding energy of the $\mathrm{N} 1 \mathrm{~s}$ peak. The partial charge on the nitrogen atom changes depending on the acidity of the barrier-type anodic oxides, leading to a change in the binding energy of the sub-peaks. Several other studies show the possibility of XPS to study interfacial interactions. ${ }^{28,48-50}$ Unfortunately, due to the high vacuum of the analysis chamber, it is not possible to use conventional XPS as an in situ analysis technique to study interfacial durability. Therefore, often the failed surfaces after water exposure are investigated by XPS or time of flight secondary ions mass spectroscopy (ToF-SIMS)..$^{51-53}$

It can be concluded that the use of model molecule adsorption provides an easy way to study interactions between functional groups and the substrate, however these monomeric compounds do not have the same bulk properties as polymeric coatings.

\section{The thin-film methodology to study interfacial interactions}

In order to investigate more realistic model systems, a thin-film approach is often used. With this approach, it becomes possible to study the interface by the deposition of a sufficiently thin layer, commonly of the order of a couple of nanometers, that allows to probe the interface directly by surface analysis techniques in a non-destructive and in situ way. Depending on what analysis technique is used, the thin film can either be the polymer layer or the metal oxide film.

Vibrational spectroscopic approaches have shown to be very useful to probe the adsorption of macromolecules from solution onto a metal surface. IRRAS, as introduced in the previous section, can also be applied for the study of ultrathin polymer film adsorption on metal oxides. Konstadinidis et al. ${ }^{54}$ and Tannenbaum et al. ${ }^{55}$ used this technique to monitor in situ the kinetics of acrylic polymers, such as PMMA adsorption onto aluminum oxide. Besides the study of acid-base interfacial interactions of hybrid systems, IRRAS also finds many applications in the study of selfassembling monolayers (SAM) layers and protein/metal oxide interactions. ${ }^{56,57}$
A combination of Raman spectroscopy and spectroscopic ellipsometry was utilized by Van Schaftinghen et al. ${ }^{58}$ to obtain chemical and morphological information of a polypyrolle/iron hybrid system. However, this approach leads to a qualitative study of the interface. In order to obtain chemical information directly from the interface, surface enhanced Raman spectroscopy (SERS) needs to be utilized in order to obtain a high enough sensitivity to study adsorption/desorption processes. In order to invoke the SERS effect, a nanostructured (often noble) metal surface is required. This leads to enhancement factors of $10^{10}$ to $10^{11}$ that allows to probe single molecules. Research is often performed on rough $\mathrm{Au}$ or $\mathrm{Ag}$ deposited metal films, which are beyond the scope of this review paper. ${ }^{59}$ Nevertheless, some examples of SERS exist on roughed iron or copper surfaces and this in combination with electrochemical techniques to study hybrid systems in situ. ${ }^{60}$ It has been proposed to utilize metal oxide nanoparticles (MONPs) for SERS purposes in order to study polymer/metal oxide interfaces in situ. ${ }^{8,61}$

The use of XPS to study the interface of ultrathin polymer films on metal oxide substrates is a powerful approach since changes in the binding energy spectrum can be linked to specific binding states of molecules at the interface. By depositing ultrathin poly (methyl methacrylate) layers on different metal oxides, the formation of a carboxylate chemical bond and hydrogen bonding could be identified by XPS. ${ }^{62,63}$ Also for other acrylic polymers, the formation of hydrogen and chemical bonds at the interface were characterized by XPS. ${ }^{64-66}$

Owing to the ultra-high vacuum of the analysis chamber of XPS, it is not possible to study these hybrid systems in situ. Recent developments in the field of near-ambient pressure XPS (NAPXPS) allow to increase the pressure in the XPS analysis chamber. Thanks to the combination of differential pumping and electrostatic lenses, it is made possible to perform photoelectron spectroscopy under elevated gas pressures of about 25 mbar. ${ }^{67}$ Owing to the fact that high-photon fluxes are required, NAPXPS systems can mainly be found at synchrotron facilities. On the other hand, polymer systems tend to degrade under high-photon fluxes, therefore the study of hybrid systems by NAPXPS is not widespread. Fortunately, the recent development of lab-based NAPXPS with a conventional Al $\mathrm{K}$ a source makes it possible to study ultrathin polymer films under near-ambient conditions. Pletincx et al. ${ }^{68,69}$ used a lab-based NAPXPS to study the effect of humidity on ultrathin acrylic polymers deposited on aluminum oxide surfaces. Changes in the C 1s XPS spectra, shown in Fig. 4, at varying water vapor pressures indicate more carboxylate anion formation due to the presence of water. They observed that water plays an important role in the formation of carboxylate bonds and has an impact on the stability of the formed ionic bonds. The application of photoelectron spectroscopy under more realistic pressures is an extremely powerful tool for the study of the formation and degradation of interfaces between ultrathin organic films and metal oxide surfaces. ${ }^{8}$

It is also possible to study the interface by approaching this region from the metal oxide side. This was demonstrated by Watts et al. ${ }^{70}$ who dissolved the metal substrate without dissolving the thin metal oxide. Owing to this approach, it was possible to study the interactions between a polybutadiene coating and low carbon steel by XPS. This study showed that a boundary layer was formed and that $\mathrm{Fe}(\mathrm{III})$ at the interface was reduced to $\mathrm{Fe}(\mathrm{II})$ due to the curing reaction of the polybutadiene. This approach was also applied to laminated aluminum systems used for beverage cans. Taheri et al. ${ }^{13}$ followed a similar procedure and sputtered away the $\mathrm{Zn}$ metal with Ar-ions from a micrometer thin metal sheet in order to reach the interface. High-resolution XPS resulted in chemical state information, showing the formation of a carboxylate bond for an adsorbed model molecule compound.

Attenuated total reflectance Fourier transform infrared spectroscopy (ATR-FTIR) has mainly been used to study the uptake of 


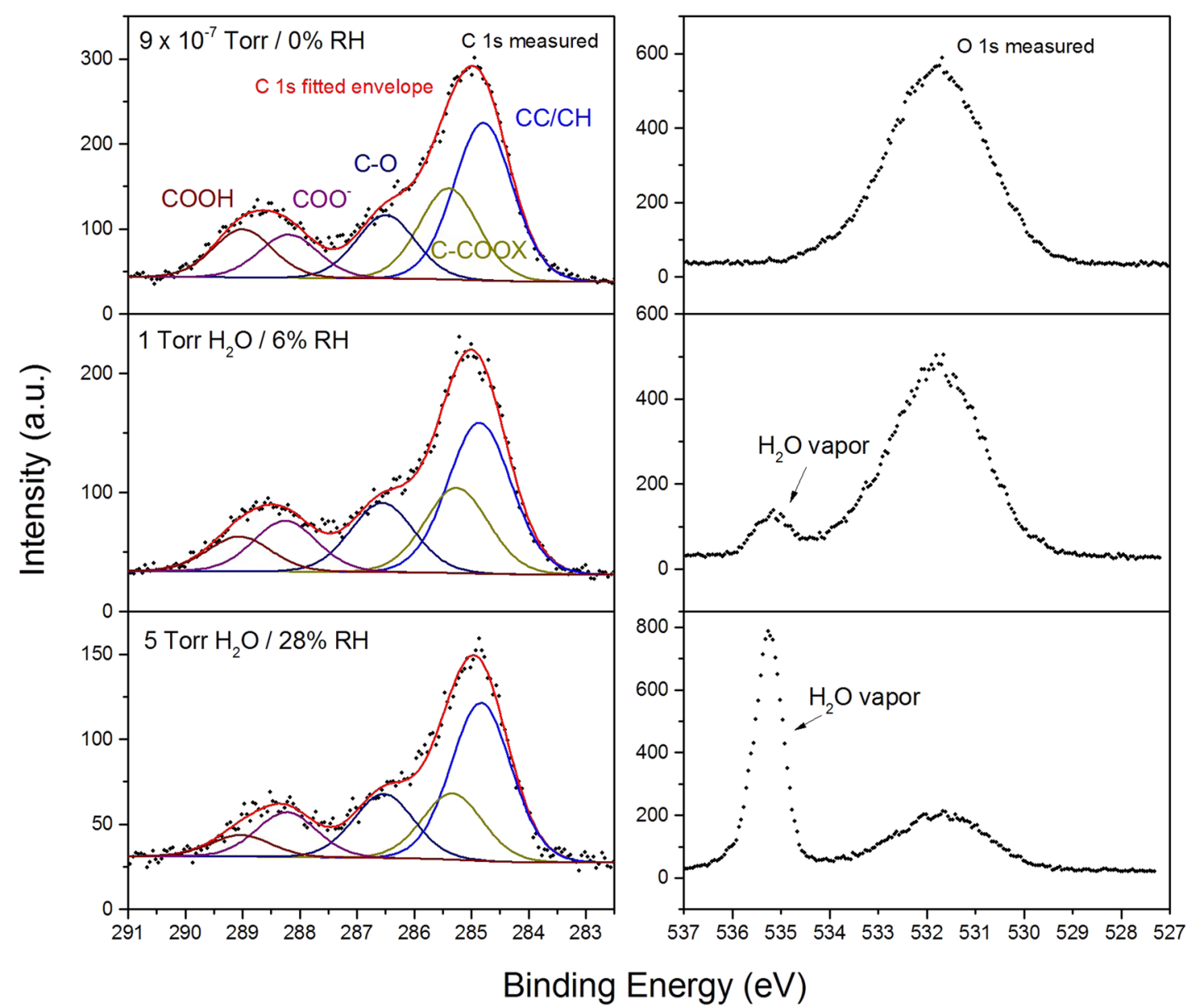

Fig. $4 \mathrm{C} 1 \mathrm{~s}$ (left) and $\mathrm{O} 1 \mathrm{~s}$ (right) NAPXPS spectra of an ultrathin PAA film on native aluminum oxide at varying water vapor pressures. $9 \times 10^{-7}$ Torr (a), 1 Torr $\mathrm{H}_{2} \mathrm{O}(\mathbf{b}), 5$ Torr $\mathrm{H}_{2} \mathrm{O}$ (c). Increasing the water vapor pressure leads to a shift to lower binding energy, indicating more carboxylate anions due to water. ${ }^{68}$ Reprinted from Pletincx et al. Copyright (2017) Springer Nature

water in polymer/metal oxide systems due to the strong adsorption bands of $\mathrm{H}_{2} \mathrm{O}\left(3500\right.$ and $\left.\left.1650 \mathrm{~cm}^{-1}\right)\right)^{71,72}$ The combination of both IR and electrochemical impedance spectroscopy (EIS) to create an integrated spectroelectrochemical system was developed by Vlasak et al. ${ }^{73}$ They used a combination of ATRFTIR and EIS to in situ study water uptake in an epoxy-amine adhesive. From the IR spectra, the diffusion of water in the bulk of an epoxy-amine adhesive could be monitored as a function of water exposure time, shown in Fig. 5. By peak-fitting of the $\mathrm{OH}$ vibration band, the different states of water in the adhesive are identified. The combined analytical approach allowed the analysis of diffusion coefficients of water, the quantification of the water uptake as a function of time and its influence on the interfacial boundary layer composition. Also the combination of an integrated set-up of ATR-FTIR with scanning Kelvin probe (SKP) has been developed by Wapner et al. ${ }^{74}$ following the diffusion of $\mathrm{D}_{2} \mathrm{O}$ and the resulting de-adhesion at epoxy adhesive/iron interfaces. SKP is well suited to follow delamination fronts at buried interfaces, but the technique does not allow to directly probe chemical interactions. Notwithstanding, Wielant et al. ${ }^{75}$ showed a correlation between Volta potential shifts and acid-base interactions at the interface of epoxy coated steel surfaces. SKP is useful to study cathodic delamination reactions and interfacial bonds, but only in the case of significant dipole formation at the interface. $^{76,77}$

ATR-FTIR has a probing depth of several hundreds of nanometers to micrometers depending on the angle of incidence of the IR light and the refractive index of the internal reflective element (IRE). This makes the technique in its conventional set-up not suitable to probe chemical interactions locally at the interface. However, it is possible to study the interactions between organic layers and metal oxide interfaces by depositing an ultrathin metal film on top of the IRE element. ${ }^{78}$ This is the so-called Kretschmann configuration (IR Kretschmann), which results in an near-interface specific infrared spectrum.

Öhman et al. ${ }^{79-83}$ specifically focused on IR Kretschmann to study the interfacial behavior of water and ions at the solid/solid interface of various systems on nanometer thin aluminum oxide layers, combining this approach with impedance spectroscopy. This approach allows to monitor water and ion transport through polymer coatings as well as deterioration and/or corrosion onset globally in polymer/metal oxide systems (by EIS), while simultaneously obtaining infrared spectra of the functional groups present at the interface (by the IR Kretschmann) shown in Fig. 6. This approach was extended to zinc oxide thin metal films by Taheri et al. ${ }^{13,84}$, showing the formation of ionic bonds between the thick polymer films and the zinc oxide surface.

Pletincx et al. ${ }^{68}$ utilized IR Kretschmann to follow the adsorption process from a polyacrylic acid/methanol solution onto an aluminum oxide surface, monitoring the formation of the formed carboxylate bond and the consumption of the surface hydroxyl groups as a function of time. Acrylic coatings were studied upon exposure to an aqueous electrolyte showing that the amount of carboxylate ionic bonds increases during the first hours of water 



Fig. 5 a In situ ATR-FTIR spectra of an epoxy-amine adhesive after a variation of water exposure times. b ATR-FTIR spectra of liquid water and water after $60,000 \mathrm{~s}$ of water uptake in the epoxy-amine adhesive. Various water states in the polymer bulk are identified by peak-fitting of the $\mathrm{OH}$ vibration band. ${ }^{33}$ Reprinted from Vlasak et al., Copyright (2007), with permission from Elsevier

build-up at the interface. ${ }^{69}$ These observations show that water can initially be beneficial for bond formation between certain hybrid systems, before ultimately leading to delamination of the coating upon excessive water exposure.

Monitoring interactions at the buried interface between industrially relevant polymer coatings and metal oxide surfaces Real engineering systems consist of a complex combination of a thick polymeric matrix with a high molecular weight, binders, pigments, fillers and various additives deposited on top of the substrate. In such cases, the type of polymer/metal oxide interactions will be influenced by the mobility and orientation of the macromolecules and the presence and interactions of these various components near the interface. In literature, several methodologies exist to get useful information directly from the buried interface such as the use of cross-sectioning techniques or bombarding the hybrid system with ions to sputter until the interface is reached. ${ }^{7,85}$ However widely utilized, cross-sectioning or sputtering might induce changes to the interface, since the region under investigation is bombarded by energetic particles or is severely deformed. Care needs to be taken when utilizing a mechanical sectioning technique to get access to buried interface. In order to get a very low sputter degradation, $C_{60}$ ion or $A r$ gas cluster ions can be used in the sputter process. Owing to the cluster structure of the molecules, the energy upon impact is distributed over the ion, resulting in less induced destruction of the structure under investigation. ${ }^{86}$ Alternatively, cross-sectioning techniques such as cross section polishing (CSP) or focussed ion beam (FIB) can be utilized to obtain cross-sectioned samples with a limited risk of induced damage. However, it is impossible to study environmental effects this way, since the interface immediately becomes exposed, allowing for environmental components to induce changes before the interface is analyzed. Another method to gain access to the buried interface is by the application of ultra-low-angle microtomy (ULAM). ${ }^{87}$ This technique employs a microtome combined with ultralow angle sectioning blocks in order to expose the interface and in combination with an XPS that has a small X-ray spot size or ToF-SIMS, it is possible to investigate the interfacial interactions. However, this technique has its limitations since the sample needs to be rather thin and soft in order for the microtome to be able to cut through. ${ }^{88,89}$

Alternatively, a non-destructive technique that has the capability to directly study the buried interface of a real coating-metal oxide system is sum frequency generation (SFG). SFG is a nonlinear optical vibrational spectroscopic technique that can probe molecular structure of a surface or interface in situ with a high-surface specificity. ${ }^{90}$ The application of both visible and infrared (IR) light simultaneously generates an SFG signal probing vibrational modes that are both IR and Raman active. SFG is interface sensitive because of its selection rule, making this technique intrinsically surface and interface sensitive, with submonolayer sensitivity. A drawback of this selection rule is that any interface leads to a contribution in the SFG signal, such as the polymer/air interface. This makes the interpretation of SFG spectra complex. Lu et al. ${ }^{91,92}$ showed that the chemical composition and network structure of the polymer near the interface deviates from the bulk properties (Fig. 7). Showing that the orientation of the phenyl groups from polystyrene are tilting towards the Ag metal interface. Myers et al. ${ }^{93}$ have shown that delamination at a $\mathrm{Cu}$ / epoxy interface occurs at a weak zone within the epoxy near the interface. Ordered methyl and methylene groups as well as adsorption of amine groups at the copper surface changed the molecular structure of the cross-linked network at the copper interface. These changes lead to differences in the epoxy network structure and eventually led to delamination because of weaker mechanical properties near the interface with respect to the bulk. SFG is a promising tool to further investigate the molecular structures at buried interfaces. An extensive review on the use of SFG for unravelling adhesion at buried interfaces is provided by Zhang et al. ${ }^{94}$

\section{COVALENT BOND FORMATION: THE EFFECT OF SILANE/METAL OXIDE INTERACTIONS AS AN ADHESION PROMOTOR}

When it comes to silanes, it has become increasingly clear that chemical interactions play an important role in describing the mechanism behind their excellent adhesion properties. However, their exact binding mechanism is not yet fully understood. The most accepted hypothesis describing the binding mechanism was proposed by Plueddemann. ${ }^{95}$ His theory suggests that the silane molecules are hydrolyzed in solution to form silanol groups ( $S i$ $-\mathrm{OH}$ ). Upon deposition of these molecules onto the metal oxide surface the silanols can react further to form a combination of oxane bonds $(\mathrm{Si}-\mathrm{O}-\mathrm{Me})$ and hydrogen bonds. The hybrid system can also be cured in order for the unreacted silanol groups to condensate and form a siloxane network $(\mathrm{Si}-\mathrm{O}-\mathrm{Si})$. It is also believed that the formed hydrogen bonds are converted to covalent oxane bonds by the curing process. ${ }^{96}$

Various investigations have been carried out over time to elucidate the exact situation at the silane/metal oxide interface. A combination of ToF-SIMS, XPS and infrared spectroscopy were utilized on a variation of silanes and metal oxide types. ${ }^{97-99}$ On 




a

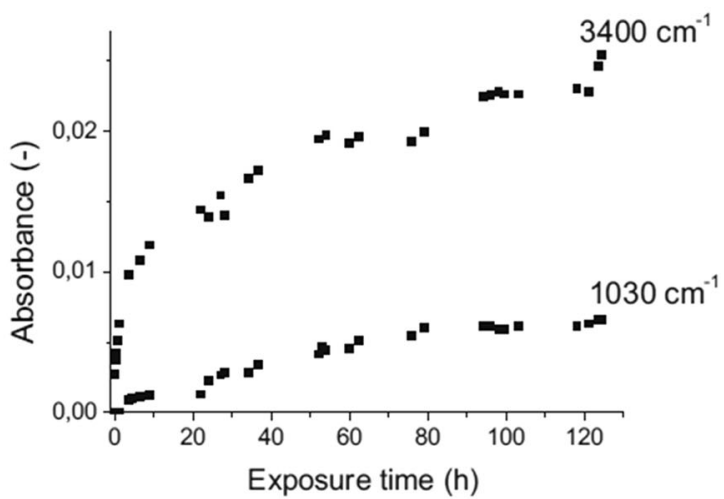

b

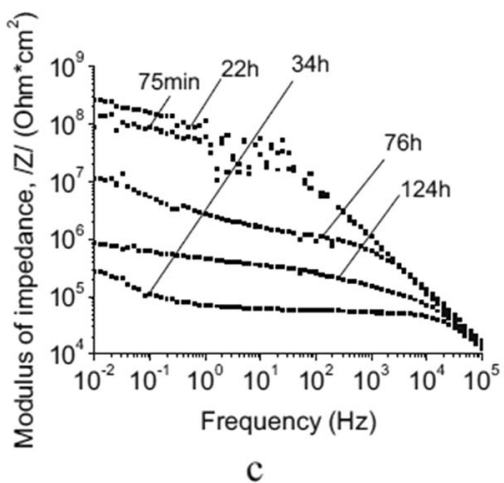

Fig. 6 a ATR-FTIR spectra in the Kretschmann geometry of a polymer/aluminum oxide interface after 75 min, 22 and $120 \mathrm{~h}$ exposure to a $1 \mathrm{M}$ NaSCN solution, $\mathbf{b}$ the time dependence of the peak maxima at 3400 and $1030 \mathrm{~cm}^{-1}$, and $\mathbf{c}$ the Bode impedance plots after $75 \mathrm{~min}, 22,34,76$, and $120 \mathrm{~h}$ exposure. ${ }^{83}$ Reprinted from Öhman et al., Copyright (2011), with permission from Elsevier

steel surfaces, Gettings and Kinloch studied the adsorption of gamma-GPS by SIMS and XPS. An $\mathrm{Fe}-\mathrm{O}-\mathrm{Si}^{+}$peak was observed in the SIMS spectra, indicating the presence of the covalent bond. ${ }^{100}$ Also Davis and Watts observed the presence of this peak in their ToF-SIMS spectra. ${ }^{101}$ For aluminum oxide, Abel et al. ${ }^{102}$ investigated a cured thin film of $\gamma$-glycidoxypropyltrimethoxysilane ( $\gamma$-GPS). A high-mass resolution ToF-SIMS spectrum made it possible to examine fragments with a nominal mass of $71 \mathrm{u}$ and $83 \mathrm{u}$, indicating the presence of $\mathrm{Al}-\mathrm{O}-\mathrm{Si}^{+}$and $\mathrm{Al}-\mathrm{O}-\mathrm{Si}-\mathrm{CH}_{2}^{+}$ secondary ions. Depth profiling showed that these fragments could still be observed, whereas the other organic fragments were eliminated from the substrate surface during the sputtering process, indicating this fragment is characteristic for the interfacial region. ${ }^{103}$ Abel et al. ${ }^{104}$ also investigated cross sections of model samples of the interface of an adhesive joint containing small levels of aminopropyl triethoxysilane (APS) by time of flight secondary ion mass spectrometry (ToF-SIMS), leading to spectra and image the interface region in between the aluminum and an epoxy adhesive. It was found from the ToF-SIMS spectra shown in Fig. 8, that APS reacted with the substrate forming a covalent bond and was also cross-linked within the adhesive.

The use of XPS in order to elucidate the presence of covalent bonds is not straightforward. Gettings and Kinloch attempted to use XPS but didnot succeed to identify the contribution of the covalent bonds in the spectra. ${ }^{100}$ Beccaria et al. ${ }^{97}$ assigned a peak at $102.6 \mathrm{eV}$ in the Si $2 \mathrm{p}$ spectra to the covalent bond of a 3trimethoxysilylpropanethiol/cupper system. Franquet et al. ${ }^{105}$ showed that the AI $2 p$ XPS spectrum of a thin hydrolyzed bis1,2-(triethoxysilyl)ethane films deposited on alkaline-cleaned aluminum oxide surface indicates the formation of $\mathrm{Al}-\mathrm{O}-\mathrm{Si}$ bonds. The presence of this interfacial interaction was confirmed by the analysis of a di-s-butoxyaluminoxytriethoxysilane (DBAS) coating that was used to obtain reference data for the binding energy of an $\mathrm{Al}-\mathrm{O}-\mathrm{Si}$ bond.

Owing to the difficulties of characterizing the bonding interactions of silane/metal oxide systems, an even more limited amount of research has been performed to directly monitor the degradation of interfacial silane/metal oxide interactions. Rattana et al. ${ }^{52}$ compared epoxy coated aluminum oxide with and without a $\gamma$-glycidoxypropyltrimethoxysilane ( $\gamma$-GPS). They observed that the adhesive adsorbed on the silane coated surface is more stable, whereas the adhesive on the non-coated sample is replaced more rapidly (also under elevated temperatures). This is explained by the aqueous stability of the formed covalent bond of the silane with respect to the acid-base interaction between the epoxy adhesive and the metal oxide.

Vibrational spectroscopy, such as in situ PM-IRRAS, has been applied for the investigation of interfacial stability of organosilane monolayer films on model metal oxide thin films. ${ }^{96,106}$ The exposure to high relative humidity for octadecyltriethoxysilane films on crystalline zinc oxide films results in physisorption of water on the metal oxide surface in the cross-linked film. The high water activity at the interface leads to a reversible wet deadhesion of the interfacial silanol groups from the model zinc oxide surface. ${ }^{96}$ However, this work mainly focuses on the changes in the hydrogen bonds but covalent bonding is not directly investigated. This can be explained due to the existence of many overlapping vibrational bands in the region where the covalent $\mathrm{Si}-\mathrm{O}-\mathrm{Me}$ band is expected in the infrared spectrum. 

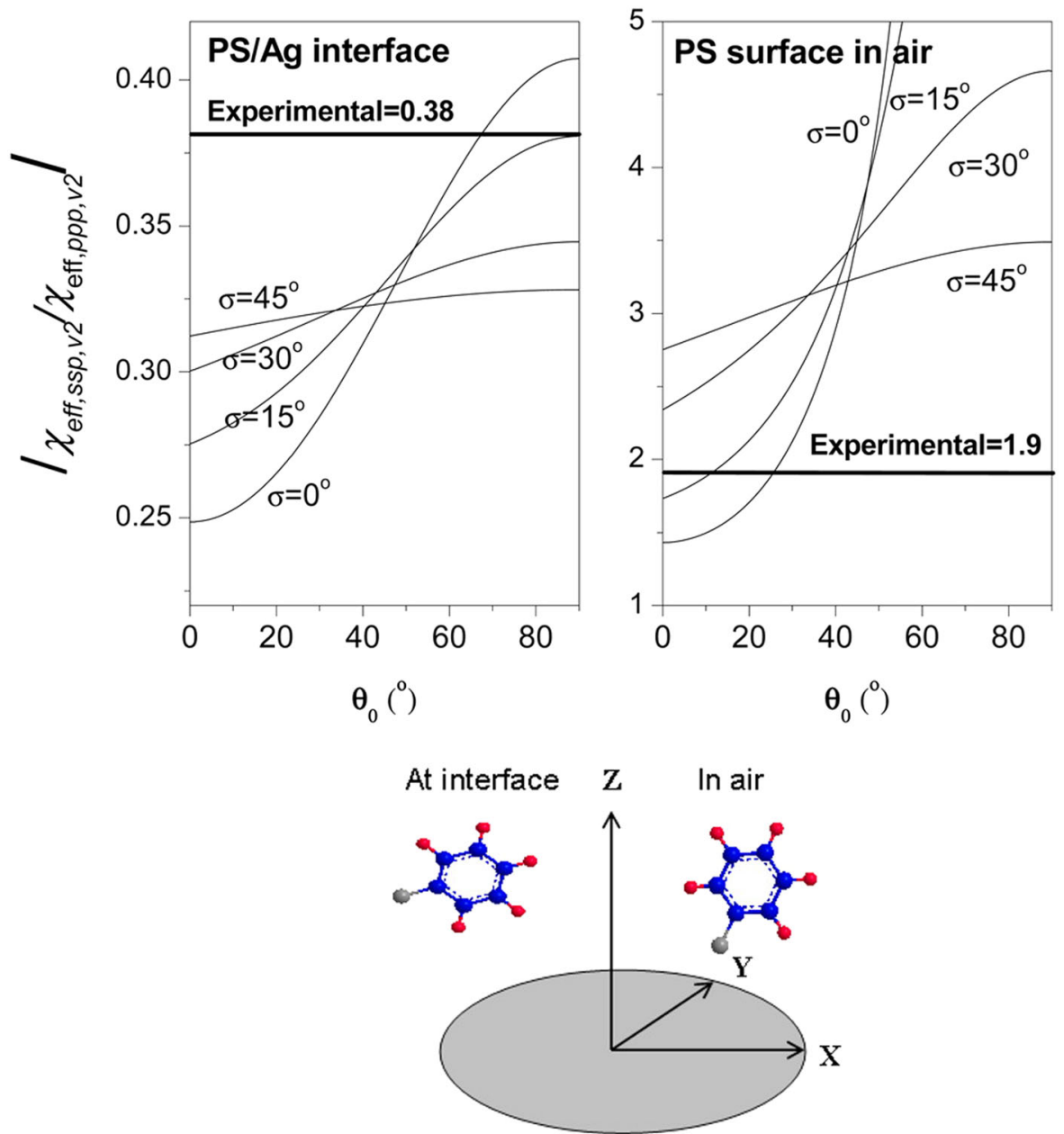

Fig. $7\left|X_{\text {eff, ssp,v2/Xeff,ppp,v2 }}\right|$ as a function of the tilt angle of the phenyl groups at the polystyrene/Ag interface and the polystyrene surface in air. The variation in tilt angle shows a different orientation of the phenyl groups at the polymer/metal interface and polymer/air interface. ${ }^{92}$ Reprinted with permission from Lu et al. Copyright (2014) American Chemical Society

IR Kretschmann was utilized to investigate adhesive/silane/ metal oxide systems by Öhman et al. ${ }^{107}$ and showed that water build-up at the interface was retarded due to the silane coating. Additionally, water-induced changes were observed in the IR spectrum but these alterations could not be clearly assigned to specific interfacial interactions, again due to the abundance and overlapping of vibrational bands in the expected region. Further research is required to elucidate the behavior of silane/metal oxide systems under environmental conditions.

Another promising approach is the application of ambient pressure hard X-ray photoelectron spectroscopy or AP-HAXPES to investigate in situ solid/liquid interfaces. Owing to the application of hard X-rays, a larger probing depth is achieved than for conventional XPS. This technique is typically synchrotron based, however lab-based devices are recently made available. ${ }^{108}$ Favaro et al. $^{109}$ accessed the buried interface between 3-aminopropyl triethoxysilane (APTES) on $\mathrm{TiO}_{2}$ surface buried by a nanometricthin layer of water and followed changes in the chemical composition and correlated band-bending upon changing the electrolyte $\mathrm{pH}$. This is achieved by the application of a "dip and pull" method and utilizing AP-HAXPES.

\section{CONCLUSION}

It becomes increasingly clear that molecular interactions at the interface play a key role in understanding the durability of polymer/metal oxide systems. However, unravelling what is exactly happening locally at industrial polymer/metal oxide interfaces is still a challenging scientific problem. The careful selection of model systems in combination with the appropriate accessing methodology allow an understanding of the formation and degradation of different physical and chemical bonds at idealized interfaces. A complex interplay of surface properties lead to different bonding conditions at the interface. The pretreatment of the metal oxide substrate prior to coating impacts interfacial bonding durability. Surface oxide properties are directly correlated to interface interactions and external influences such as adventitious carbon contamination, water adsorption, and solvent interactions are import factors that impact the oxide substrate and thus influence overall bonding. Recent developments in surface science opened up the possibility to probe the (buried) polymer/metal oxide interface in situ under (near-)realistic conditions. Model systems are carefully selected in order to mimic industrial coating/engineering metal oxide systems, however it is still challenging to investigate real coating/metal oxide interfaces directly. The characterization of ionic interactions at the interface of model polymer/metal oxide systems is reviewed, followed by a discussion on the role of covalent bonding in the use of silanes as adhesion promoters on metal oxide substrates. This review gave an overview of current state-of-the-art approaches that will help to bridge the gap between fundamental science and macroscopic 


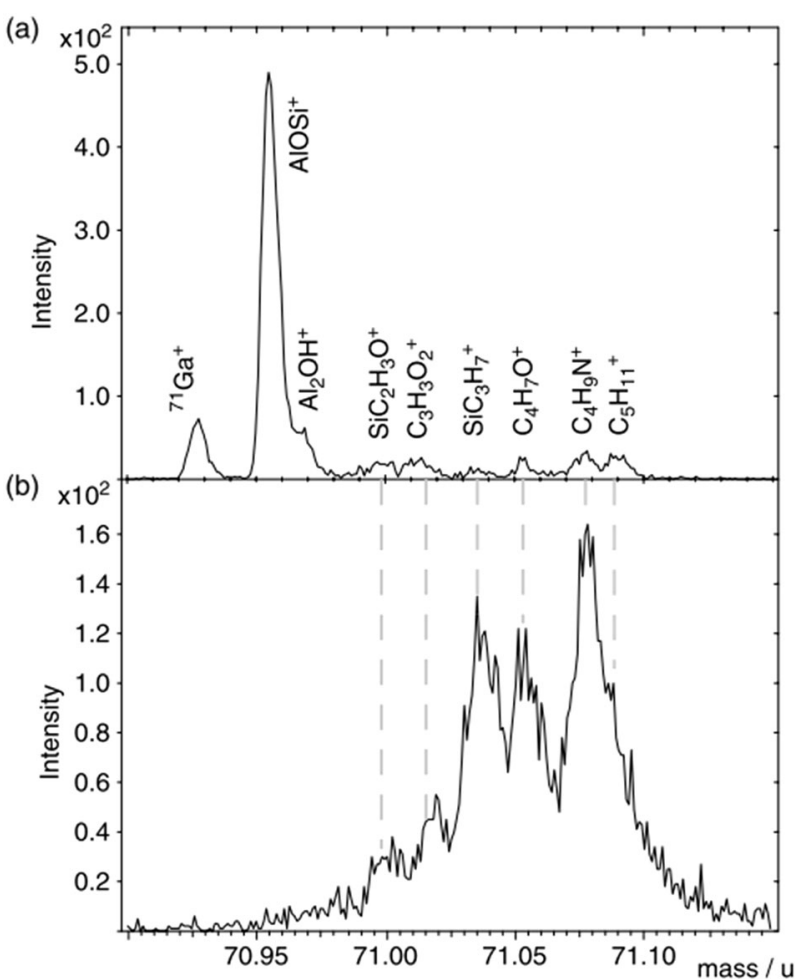

Fig. 8 a ToF-SIMS spectrum of the $\mathrm{m} / \mathrm{z} 71$ region of an area near the interface of an aminopropyl triethoxysilane (APS) layer and aluminum oxide. This spectrum shows the intense component assigned to $\mathrm{Al}-\mathrm{O}-\mathrm{Si}^{+}$, indicative of the formation of a covalent bond. b ToF-SIMS spectrum of an area closer to the epoxy/silane interface. $^{104}$ Reprinted from Abel et al., Copyright (2009), with permission from Wiley

behavior in order to eventually predict and engineer the durability of industrial hybrid systems under realistic, day-to-day conditions.

\section{ACKNOWLEDGEMENTS}

S.P., H.T., and T.H. acknowledge financial support by Research Foundation-Flanders (FWO) under project number SB-19-151. L.F. and J.M.C.M. acknowledge funding under project numbers F81.6.13509 in the framework of the Partnership Program of the Materials Innovation Institute M2i (www.m2i.nl) and the Foundation of Fundamental Research on Matter (FOM) (www.fom.nl), which is part of the Netherlands Organisation for Scientific Research NWO (www.nwo.nl).

\section{AUTHOR CONTRIBUTIONS}

S.P. wrote the main manuscript text. L.I.F., J.M.C.M., T.H., and H.T. reviewed the manuscript text. All authors have given approval to the final version of the manuscript.

\section{ADDITIONAL INFORMATION}

Competing interests: The authors declare no competing interests.

Publisher's note: Springer Nature remains neutral with regard to jurisdictional claims in published maps and institutional affiliations.

\section{REFERENCES}

1. Montemor, M. F. Functional and smart coatings for corrosion protection: $A$ review of recent advances. Surf. Coat. Technol. 258, 17-37 (2014).

2. Fowkes, F. M. \& Mostafa, M. A. Acid-base interactions in polymer adsorption. Ind. Eng. Chem. Prod. Res. Dev. 17, 3-7 (1978).
3. Packham, D. E. Handbook of Adhesion. Handbook of Adhesion: Second Edition 1 (John Wiley \& Sons, Ltd, Chichester, 2005)

4. Lee, L. -H. Molecular bonding and adhesion at polymer-metal interphases. J. Adhes. 46, 15-38 (1994).

5. Bohn, P. W. Localized optical phenomena and the characterization of materials interfaces. Annu. Rev. Mater. Sci. 27, 469-498 (1997).

6. Grundmeier, G. \& Stratmann, M. Adhesion and de-adhesion mechanisms at polymer/metal interfaces: mechanistic understanding based on in situ studies of buried interfaces. Annu. Rev. Mater. Res. 35, 571-615 (2005).

7. Watts, J. F. The interfacial chemistry of adhesion: novel routes to the holy grail? In adhesion: current research and applications (ed. Possart, W.) 1-16 (Wiley-VCH Verlag GmbH \& Co. KGaA, Weinheim, 2006). https://doi.org/10.1002/ 3527607307.ch1.

8. González-Orive, A., Giner, I., de los Arcos, T., Keller, A. \& Grundmeier, G. Analysis of polymer/oxide interfaces under ambient conditions-An experimental perspective. Appl. Surf. Sci. 442, 581-594 (2018).

9. Critchlow, G., Posner, R., Ozcan, O., Grundmeier, G. \& Critchlow, G. Design of Adhesive Joints Under Humid Conditions. in Advanced Structured Materials, Vol. 25 (eds da Silva, L. F. M. \& Sato, C.) (Springer, Berlin, Heidelberg, 2013).

10. Lyon, S., Bingham, R. \& Mills, D. Advances in corrosion protection by organic coatings: What we know and what we would like to know. Prog. Org. Coat. 102, 2-7 (2017).

11. Mayne, J. E. O. The mechanism of the inhibition of the corrosion of iron and steel by means of paint. Anti Corros. Methods Mater. 1, 286-290 (1952).

12. Funke, W. Improvement of Wet Adhesion of Organic Coatings by Thin Adhesion Layer. in Surface Phenomena and Latexes in Waterborne Coatings and Printing Technology (ed. Sharma, M.K.) 115-122 (Springer, Boston, 1995). https://doi.org/ 10.1007/978-1-4757-2395-3_9.

13. Taheri, $P$. et al. In situ study of buried interfacial bonding mechanisms of carboxylic polymers on Zn surfaces. J. Phys. Chem. C. 117, 3374-3382 (2013).

14. Arslanov, V. \& Funke, W. The effect of water on the adhesion of organic coatings on aluminium. Prog. Org. Coat. 15, 355-363 (1988).

15. Arslanov, V. V. \& Funke, W. Improvement of the resistance to water of an adhesive joint between polymers and aluminium by using thin adhesion layers. Prog. Org. Coat. 15, 365-372 (1988).

16. Gahde, J. et al. Increase in coating wet adhesion stability by highly-ordered polymers. J. Adhes. Sci. Technol. 11, 861-875 (1997).

17. Funke, W. Thin-layer technology in organic coatings. Prog. Org. Coat. 28, 3-7 (1996).

18. Kinloch, A. J. Adhesion and adhesives. (Springer Netherlands, Dordrecht, 1987).

19. Salgin, B., Özkanat, Ö., Mol, J. M. C., Terryn, H. \& Rohwerder, M. Role of surface oxide properties on the aluminum/epoxy interfacial bonding. J. Phys. Chem. C. 117, 4480-4487 (2013).

20. Özkanat, Ö., de Wit, F. M., de Wit, J. H. W., Terryn, H. \& Mol, J. M. C. Influence of pretreatments and aging on the adhesion performance of epoxy-coated aluminum. Surf. Coat. Technol. 215, 260-265 (2013).

21. Abrahami, S. T., Hauffman, T., de Kok, J. M., Terryn, H. \& Mol, J. M. The role of acid-base properties in the interactions across the oxide-primer interface in aerospace applications. Surf. Interface Anal. 48, 712-720 (2016).

22. Critchlow, G. W. \& Brewis, D. M. Review of surface pretreatments for aluminium alloys. Int. J. Adhes. Adhes. 16, 255-274 (1996).

23. Castle, J. E. The composition of metal surfaces after atmospheric exposure: an historical perspective. J. Adhes. 84, 368-388 (2008).

24. Baldan, A. Adhesively-bonded joints and repairs in metallic alloys, polymers and composite materials: Adhesives, adhesion theories and surface pretreatment. J. Mater. Sci. 39, 1-49 (2004).

25. Bland, D. J., Kinloch, A. J. \& Watts, J. F. The role of the surface pretreatment in the durability of aluminium-alloy structural adhesive joints: Mechanisms of failure. J. Adhes. 89, 369-397 (2013).

26. Watts, J. F., Chehimi, M. M. \& Gibson, E. M. Acid-base interactions in adhesion: the characterization of surfaces \& interfaces by XPS. J. Adhes. 39, 145-156 (1992).

27. McCafferty, E. \& Wightman, J. P. Determination of the concentration of surface hydroxyl groups on metal oxide films by a quantitative XPS method. Surf. Interface Anal. 26, 549-564 (1998).

28. Wielant, J., Hauffman, T., Blajiev, O., Hausbrand, R. \& Terryn, H. Influence of the iron oxide acid-base properties on the chemisorption of model epoxy compounds studied by XPS. J. Phys. Chem. C. 111, 13177-13184 (2007).

29. Van Den Brand, J. On the adhesion between aluminium and polymers. Ph.D thesis, The Netherlands (2004)

30. Alexander, M. R., Thompson, G. E. \& Beamson, G. Characterization of the oxide/ hydroxide surface of aluminum using $X$-ray photoelectron spectroscopy: A procedure for curve fitting the $01 \mathrm{~s}$ core level. Surf. Interface Anal. 29, 468-477 (2000). 
31. Taheri, P. et al. Molecular interactions of electroadsorbed carboxylic acid and succinic anhydride monomers on zinc surfaces. J. Phys. Chem. C. 115 17054-17067 (2011)

32. Taheri, P. et al. Effects of surface treatment and carboxylic acid and anhydride molecular dipole moments on the Volta potential values of zinc surfaces. J. Phys. Chem. C. 117, 1712-1721 (2013).

33. Abrahami, S. T. et al. Interface strength and degradation of adhesively bonded porous aluminum oxides. NPJ Mater. Degrad. 1, 8 (2017).

34. Abrahami, S. T., Hauffman, T., De Kok, J. M. M., Mol, J. M. C. \& Terryn, H. XPS analysis of the surface chemistry and interfacial bonding of barrier-type $\mathrm{Cr}(\mathrm{VI})$ free anodic oxides. J. Phys. Chem. C. 119, 19967-19975 (2015).

35. McCafferty, E. \& Wightman, J. Determination of the surface isoelectric point of oxide films on metals by contact angle titration. J. Colloid. Interface. Sci. 194, 344-55 (1997).

36. Abel, M. L. \& Chehimi, M. M. Effect of acid-base interactions on the adsorption of PMMA on chloride-doped polypyrrole from neutral, acidic and basic solvents: an XPS study. Synth. Met. 66, 225-233 (1994).

37. Greenler, R. G. Infrared study of the adsorption of methanol and ethanol on magnesium oxide. J. Chem. Phys. 37, 2094-2100 (1962).

38. Hauffman, T. et al. Measuring the adsorption of ethanol on aluminium oxides using odd random phase multisine electrochemical impedance spectroscopy. Electrochem. Commun. 22, 124-127 (2012).

39. Pletincx, S. et al. Infrared study of the adsorption of methanol and ethanol on magnesium oxide. J. Chem. Phys. 37, 2094-2100 (1962).

40. Brand, VanDen et al. Ageing of aluminium oxide surfaces and their subsequent reactivity towards bonding with organic functional groups. Appl. Surf. Sci. 235, 465-474 (2004)

41. Pletincx, S., Abrahami, S., Mol, J. M. C., Hauffman, T. \& Terryn, H. Advanced (In Situ) surface analysis of organic coating/metal oxide interactions for corrosion protection of passivated metals. in Encyclopedia of Interfacial Chemistry (ed. Wandelt, K.) 1-17 (Elsevier, Amsterdam, 2018). https://doi.org/10.1016/B978-012-409547-2.13773-4.

42. van den Brand, J., Blajiev, O., Beentjes, P. C. J., Terryn, H. \& de Wit, J. H. W. Interaction of anhydride and carboxylic acid compounds with aluminum oxide surfaces studied using infrared reflection absorption spectroscopy. Langmuir: ACS J. Surf. colloids 20, 6308-6317 (2004).

43. Beentjes, P. C. J., Van Den Brand, J. \& De Wit, J. H. W. Interaction of ester and acid groups containing organic compounds with iron oxide surfaces. J. Adhes. Sci. Technol. 20, 1-18 (2006)

44. Taheri, P. et al. Electrochemical analysis of the adsorption and desorption behaviors of carboxylic acid and anhydride monomers onto zinc surfaces. Electrochim. Acta 56, 9317-9323 (2011).

45. Ramin, M. A. et al. PM-IRRAS investigation of self-assembled monolayers grafted onto SiO2/Au substrates. Langmuir 27, 6076-6084 (2011).

46. Thissen, P., Valtiner, M. \& Grundmeier, G. Stability of phosphonic acid selfassembled monolayers on amorphous and Single-crystalline aluminum oxide surfaces in aqueous solution. Langmuir 26, 156-164 (2010).

47. Maxisch, M., Thissen, P., Giza, M. \& Grundmeier, G. Interface chemistry and molecular interactions of phosphonic acid self-assembled monolayers on oxyhydroxide-covered aluminum in humid environments. Langmuir 27, 6042-6048 (2011).

48. Blajiev, O. O., Ithurbide, A., Hubin, A., Van Haesendonck, C. \& Terryn, H. XPS study of the assembling morphology of 3-hydroxy-3-phosphono-butiric acid tert-butyl ester on variously pretreated Al surfaces. Prog. Org. Coat. 63, 272-281 (2008).

49. Taheri, P. et al. A comparison of the interfacial bonding properties of carboxylic acid functional groups on zinc and iron substrates. Electrochim. Acta 56, 1904-1911 (2011).

50. Fockaert, L. I. et al. Zirconium-based conversion film formation on zinc, aluminium and magnesium oxides and their interactions with functionalized molecules. Appl. Surf. Sci. 423, 817-828 (2017).

51. Di Ruocco, V., Morra, M., Occhiello, E. \& Garbassi, F. On the failure of waterimmersed steel-acrylic adhesive joints. J. Mater. Sci. Lett. 10, 649-652 (1991).

52. Rattana, A., Abel, M. -L. \& Watts, J. F. Degradation of interfacial chemistry of epoxy/silane/aluminium interfaces as a result of aqueous attack. J. Adhes. 81, 963-988 (2005)

53. Ghaffari, M., Saeb, M. R., Ramezanzadeh, B. \& Taheri, P. Demonstration of epoxy/ carbon steel interfacial delamination behavior: Electrochemical impedance and X-ray spectroscopic analyses. Corros. Sci. 102, 326-337 (2016).

54. Konstadinidis, K. et al. Segment level chemistry and chain conformation in the reactive adsorption of poly(methyl methacrylate) on aluminum oxide surfaces. Langmuir 8, 1307-1317 (1992).

55. Tannenbaum, R., King, S., Lecy, J., Tirrell, M. \& Potts, L. Infrared study of the kinetics and mechanism of adsorption of acrylic polymers on alumina surfaces. Langmuir 20, 4507-4514 (2004).
56. Brogly, M., Nardin, M. \& Schultz, J. Evidence of acid-base interfacial adducts in various polymer/metal systems by IRAS: Improvement of adhesion. J. Adhes. 58, 263-279 (1996).

57. Gregoriou, V. G. \& Rodman, S. E. in Handbook of Vibrational Spectroscopy (ed. Griffiths, P. R.) 2670-2693 (John Wiley \& Sons, Ltd, Chichester, UK, 2006).

58. Van Schaftinghen, T., Joiret, S., Deslouis, C. \& Terryn, H. In-situ Raman Spectroscopy and Spectroscopic Ellipsometry study of the iron/Polypyrrole interface. in Passivation of Metals and Semiconductors, and Properties of Thin Oxide Layers (eds Marcus, P. \& Maurice, V.) 691-696 (Elsevier, Amsterdam, 2006). https://doi. org/10.1016/B978-044452224-5/50105-0.

59. Xue, G., Lu, Y. \& Zhang, J. Stable SERS substrates used for in situ studies of the polymer-metal interface at elevated temperature. Macromolecules 27, 809-813 (1994).

60. Li, L. et al. Metal oxide nanoparticle mediated enhanced Raman scattering and its use in direct monitoring of interfacial chemical reactions. Nano Lett. 12, 4242-4246 (2012)

61. Lee, N., Schuck, P. J., Nico, P. S. \& Gilbert, B. Surface enhanced Raman spectroscopy of organic molecules on magnetite $\left(\mathrm{Fe}_{3} \mathrm{O}_{4}\right)$ nanoparticles. J. Phys. Chem. Lett. 6, 970-974 (2015).

62. Papirer, E., Perrin, J., Nanse, G. \& Fioux, P. Adsorption of poly (methylmethacrylate) on an a-alumina: evidence of formation of surface carboxylate bonds. Eur. Polym. J. 30, 985-991 (1994).

63. Watts, J. F., Leadley, S. R., Castle, J. E. \& Blomfield, C. J. Adsorption of PMMA on oxidized $\mathrm{Al}$ and Si substrates: An investigation by high-resolution X-ray photoelectron spectroscopy. Langmuir 16, 2292-2300 (2000).

64. Leadley, S. R. \& Watts, J. F. The use of XPS to examine the interaction of PMMA with oxidised metal substrates. J. Electron Spectrosc. Relat. Phenom. 85, 107-121 (1997).

65. Marsh, J., Minel, L., Barthes-Labrousse, M. G. \& Gorse, D. Interaction of epoxy model molecules with aluminium, anodised titanium and copper surfaces: an XPS study. Appl. Surf. Sci. 133, 270-286 (1998).

66. Alexander, M. R., Beamson, G., Blomfield, C. J., Leggett, G. \& Duc, T. M. Interaction of carboxylic acids with the oxyhydroxide surface of aluminium: Poly(acrylic acid), acetic acid and propionic acid on pseudoboehmite. J. Electron Spectrosc. Relat. Phenom. 121, 19-32 (2001).

67. Ogletree, D. F., Bluhm, H., Hebenstreit, E. D. \& Salmeron, M. Photoelectron spectroscopy under ambient pressure and temperature conditions. Nuclear Instruments and Methods in Physics. Res., Sect. A: Accel., Spectrometers, Detect. Assoc. Equip. 601, 151-160 (2009).

68. Pletincx, S. et al. In situ characterization of the initial effect of water on molecular interactions at the interface of organic/inorganic hybrid systems. Sci. Rep. 7, 45123 (2017).

69. Pletincx, S. et al. Unravelling the chemical influence of water on the PMMA/ aluminum oxide hybrid interface in situ. Sci. Rep. 7, 13341 (2017).

70. Watts, J. F. \& Castle, J. E. The application of X-ray photoelectron spectroscopy to the study of polymer-to-metal adhesion. J. Mater. Sci. 18, 2987-3003 (1983).

71. Nguyen, T., Bentz, D. \& Byrd, E. Method for measuring water diffusion in a coating applied to a substrate. J. Coat. Technol. 67, 37-46 (1995).

72. Linossier, I., Gaillard, F., Romand, M. \& Nguyen, T. A spectroscopic technique for studies of water transport along the interface and hydrolytic stability of polymer/substrate systems. J. Adhes. 70, 221-239 (1999).

73. Vlasak, R., Klueppel, I. \& Grundmeier, G. Combined EIS and FTIR-ATR study of water uptake and diffusion in polymer films on semiconducting electrodes. Electrochim. Acta 52, 8075-8080 (2007).

74. Wapner, K., Stratmann, M. \& Grundmeier, G. In situ infrared spectroscopic and scanning Kelvin probe measurements of water and ion transport at polymer/ metal interfaces. Electrochim. Acta 51, 3303-3315 (2006).

75. Wielant, J. \& Posner, R. SKP as a tool to study the physicochemical interaction at buried metal-coating interfaces. Surf. Interface Anal. 42, 1005-1009 (2010).

76. Posner, R., Wapner, K., Stratmann, M., Grundmeier, G. \& Titz, T. Transport processes of hydrated ions at polymer/oxide/metal interfaces. Electrochim. Acta 54, 891-899 (2009).

77. Vijayshankar, D. et al. Probing the buried metal-organic coating interfacial reaction kinetic mechanisms by a hydrogen permeation based potentiometric approach. J. Electrochem. Soc. 163, C778-C783 (2016).

78. Suzuki, Y., Osawa, M., Hatta, A. \& Suëtaka, W. Mechanism of absorption enhancement in infrared ATR spectra observed in the Kretschmann configuration. Appl. Surf. Sci. 33-34, 875-881 (1988).

79. Öhman, M., Persson, D. \& Leygraf, C. In situ ATR-FTIR studies of the aluminium / polymer interface upon exposure to water and electrolyte. Prog. Org. Coat. 57 78-88 (2006)

80. Öhman, M. \& Persson, D. An integrated in situ ATR-FTIR and EIS set-up to study buried metal-polymer interfaces exposed to an electrolyte solution. Electrochim. Acta 52, 5159-5171 (2007). 
81. Öhman, M., Persson, D. \& Leygraf, C. A Spectroelectrochemical study of metal/ polymer interfaces by simultaneous in situ ATR-FTIR and EIS. Electrochem. SolidState Lett. 10, C27-C30 (2007).

82. Öhman, M. Development of ATR-FTIR Kretschmann Spectroscopy for In situ Studies of Metal/Polymer Interfaces and its Integration with EIS for Exposure to Corrosive Conditions. Ph.D thesis, Sweden (2010).

83. Öhman, M., Persson, D. \& Jacobsson, D. In situ studies of conversion coated zinc/ polymer surfaces during exposure to corrosive conditions. Prog. Org. Coat. 70, 16-22 (2011).

84. Taheri, P., De Wit, J. H. W., Terryn, H. \& Mol, J. M. C. In situ study of buried metalpolymer interfaces exposed to an aqueous solution by an integrated ATR-FTIR and electrochemical impedance spectroscopy system. J. Phys. Chem. C. 117, 20826-20832 (2013)

85. Ho, P. S. et al. Chemical bonding and reaction at metal/polymer interfaces. J. Vac. Sci. Technol. A: Vac., Surf., Films 3, 739 (1985).

86. Chen, Y. Y. et al. X-ray photoelectron spectrometry depth profiling of organic thin films using C60 sputtering. Anal. Chem. 80, 501-505 (2008).

87. Hinder, S. J., Watts, J. F. \& Lowe, C. Interface analysis and compositional depth profiling by XPS of polymer coatings prepared using ultra-low-angle microtomy. Surf. Interface Anal. 36, 1032-1036 (2004).

88. Hinder, S. J., Lowe, C., Maxted, J. T. \& Watts, J. F. Migration and segregation phenomena of a silicone additive in a multilayer organic coating. Prog. Org. Coat. 54, 104-112 (2005)

89. Adhami, S., Abel, M. L., Lowe, C. \& Watts, J. F. The role of the adhesion promoter in a model water-borne primer. Surf. Interface Anal. 46, 1005-1008 (2014).

90. Chen, $Z$. Investigating buried polymer interfaces using sum frequency generation vibrational spectroscopy. Prog. Polym. Sci. 35, 1376-1402 (2010).

91. Lu, X. et al. Directly probing molecular ordering at the buried polymer/metal interface. Macromolecules 42, 9052-9057 (2009).

92. Lu, X., Myers, J. N. \& Chen, Z. Molecular ordering of phenyl groups at the buried polystyrene/metal interface. Langmuir: ACS J. Surf. colloids 30, 9418-22 (2014).

93. Myers, J. N. \& Chen, Z. Polymer molecular behaviors at buried polymer/metal and polymer/polymer interfaces and their relations to adhesion in packaging. J. Adhes. 93, 1081-1103 (2017).

94. Zhang, C. Sum frequency generation vibrational spectroscopy for characterization of buried polymer interfaces. Appl. Spectrosc. 71, 1717-1749 (2017).

95. Plueddemann, E. P. Adhesion through silane coupling agents. J. Adhes. 2, 184-201 (1970).

96. Torun, B., Giner, I., Grundmeier, G. \& Ozcan, O. In situ PM-IRRAS studies of organothiols and organosilane monolayers-ZnO interfaces at high water activities. Surf. Interface Anal. 49, 71-74 (2017).

97. Beccaria, A. M. \& Bertolotto, C. Inhibitory action of 3-trimethoxysilylpropanethiol1 on copper corrosion in $\mathrm{NaCl}$ solutions. Electrochim. Acta 42, 1361-1371 (1997).

98. Naviroj, S., Koenig, J. \& Ishida, H. Diffuse reflectance Fourier transform infrared spectroscopic study of chemical bonding and hydrothermal stability of an aminosilane on metal oxide surfaces. J. Adhes. 18, 93-110 (1985).
99. Song, J. \& Van Ooij, W. J. Bonding and corrosion protection mechanisms of gamma-APS and BTSE silane films on aluminum substrates. J. Adhes. Sci. Technol. 17, 2191-2221 (2003).

100. Gettings, M. \& Kinloch, A. J. Surface analysis of polysiloxane/metal oxide interfaces. J. Mater. Sci. 12, 2511-2518 (1977).

101. Davis, S. J. \& Watts, J. F. Organization of methoxysilane molecules on iron. Int. J. Adhes. Adhes. 16, 5-15 (1996).

102. Abel, M.I, Digby, R. P., Fletcher, I. W. \& Watts, J. F. Evidence of specific interaction between $\gamma$-glycidoxypropyltrimethoxysilane and oxidized aluminium using high-mass resolution ToF-SIMS. Surf. Interface Anal. 29, 115-125 (2000).

103. Batan, A. et al. Evidence of covalent bond formation at the silane-metal interface during plasma polymerization of bis-1,2- (triethoxysilyl) ethane (BTSE) on aluminium. Chem. Phys. Lett. 493, 107-112 (2010).

104. Abel, M. L. \& Watts, J. Examination of the interface of a model adhesive joint by surface analysis: A study by XPS and ToF-SIMS. Surf. Interface Anal. 41, 508-516 (2009).

105. Franquet, A., Biesemans, M., Terryn, H., Willem, R. \& Vereecken, J. Study of the interaction of hydrolysed silane solutions with pre-treated aluminium substrates. Surf. Interface Anal. 38, 172-175 (2006).

106. Grundmeier, G., Matheisen, E. \& Stratmann, M. Formation and stability of ultrathin organosilane polymers on iron. J. Adhes. Sci. Technol. 10, 573-588 (1996).

107. Öhman, M. \& Persson, D. ATR-FTIR Kretschmann spectroscopy for interfacial studies of a hidden aluminum surface coated with a silane film and epoxy I. Characterization by IRRAS and ATR-FTIR. Surf. Interface Anal. 44, 133-143 (2012).

108. Regoutz, A. et al. A novel laboratory-based hard X-ray photoelectron spectroscopy system. Rev. Sci. Inst. 89, 1-10 (2018).

109. Favaro, M. et al. Interface science using ambient pressure hard X-ray photoelectron spectroscopy. Surfaces 2, 78-99 (2019).

(i) Open Access This article is licensed under a Creative Commons Attribution 4.0 International License, which permits use, sharing, adaptation, distribution and reproduction in any medium or format, as long as you give appropriate credit to the original author(s) and the source, provide a link to the Creative Commons license, and indicate if changes were made. The images or other third party material in this article are included in the article's Creative Commons license, unless indicated otherwise in a credit line to the material. If material is not included in the article's Creative Commons license and your intended use is not permitted by statutory regulation or exceeds the permitted use, you will need to obtain permission directly from the copyright holder. To view a copy of this license, visit http://creativecommons. org/licenses/by/4.0/.

(c) The Author(s) 2019 